\title{
EFFECTS OF NITRIDING SUBSEQUENT TITANALITING OF STEELS
}

\author{
Andrei Mihai GHINEA ${ }^{1}$, Mihai Ovidiu COJOCARU ${ }^{1,3}$, \\ Leontin Nicolae DRUG $\grave{A}^{2,3}$ \\ ${ }^{1}$ Politehnica University of Bucharest, Romania \\ ${ }^{2}$ UTTIS Industries Bucharest, Romania \\ ${ }^{3}$ Academy of Technical Science of Romania \\ e-mail: cojocarumihaiovidiu@yahoo.co.uk
}

\begin{abstract}
The paper presents the results of nitriding in partially dissociated ammonia of the pure technical iron, respectively 34CrAlMo5 steel after titanaliting in powdery solid medium, with direct reference on the growth kinetics of the layers, the phase composition and the morphology of the resulting layers. Thermodynamics was anticipated and experimentally demonstrated that the layers of titanium aluminide formed on the surfaces of the two metallic materials considered do not constitute barriers to nitrogen diffusion during the nitriding process, but actively participate in the formation of simple or complex nitrides of the two elements, titanium and aluminum. On the other hand, in the presence of these layers, the flux of nitrogen atoms is slightly diminished with repercussions on the dimensions of the structural components of the layer. The conclusion of the experimental research was that the role of titanaliting prior to nitriding is to increase the proportion of the hardening phases in the surface layers of thermochemically processed metal products after nitriding.
\end{abstract}

KEYWORDS: titanaliting; nitriding; thermodynamics of the conversion of aluminides to nitrides, formation of kinetic layer, optical microscopy, electronic microscopy

\section{Introduction}

The kinetics of nitrided layers formation, their phase composition and their properties are strongly influenced by the chemical composition of the matrix subjected to processing. The alloying elements, depending on their nature and properties, influence these aspects in different ways. The phase composition of the nitrided layers, depending on the temperature at which the thermochemical processing was performed, after slow cooling, varies from the average-metal matrix interface to their deep areas, as it follows: at temperatures below $590{ }^{\circ} \mathrm{C}$ : $\varepsilon^{+} \gamma^{\prime} \rightarrow \gamma^{\prime} \rightarrow \alpha_{N}+\gamma^{\prime}{ }_{\text {exc }} \rightarrow \alpha$, and at temperatures above $590{ }^{\circ} \mathrm{C}: \varepsilon+\gamma^{\prime} \rightarrow \gamma^{\prime} \rightarrow$ eutectoid $\left(\alpha_{N}+\gamma^{\prime}\right)_{\rightarrow} \alpha_{N}+\gamma^{\prime}{ }_{\text {exc }} \rightarrow \alpha$.

It is observed that in the area adjacent to the surface (in the compounds area) appears a succession of nitride phases, in the case of iron and its alloys there order is $\varepsilon-\mathrm{Fe}_{2-3} \mathrm{~N}$ and $\gamma^{\prime}-\mathrm{Fe}_{4} \mathrm{~N}$. Depending on the composition of the matrix, the type and the proportion of nitrides also change [1-4, 10]. Most alloying elements (Cr, Mo, Mn, etc.) except $\mathrm{Al}, \mathrm{Ti}, \mathrm{Si}$, dissolve during the $\varepsilon(\mathrm{Fe}, \mathrm{Me})_{2-3} \mathrm{~N}$, causing a decrease of size and nitrogen content of this phase. Aluminium, titanium and silicon favour the development of the $\gamma^{\prime}$ $(\mathrm{Fe}, \mathrm{Me})_{4} \mathrm{~N}$, phase, separated either continuously or in acicular / platelet form on the crystalline grains limit or on the sliding planes, a phenomenon that frequently determines, the fragility of this area. High values of nitrogen concentration in the nitride layer create the necessary conditions for the appearance of the $\xi-\left(\mathrm{Fe}_{2} \mathrm{~N}\right)$, phase, separated during cooling in those areas of the $\varepsilon$ phase in which the nitrogen concentration reached values of 11-11.32\% mass [4].

In the case of steel nitriding in ammonia atmosphere, a strong migration of carbon from the matrix to the surface is registered, which determines a carbon saturation of the $\varepsilon$ phase and consequently the appearance of carbonitride $\mathrm{Fe}_{2-3}(\mathrm{~N}, \mathrm{C})$ [5]. Nitriding at high nitrogen potential atmospheres can determine the fragility of the areas adjacent to this surface and the appearance of pores. The appearance of pores is 
related to the meta-stability of nitrides. Experimentally, it was demonstrated that the porosity of the $\varepsilon$ - phase occurs at nitrogen concentrations higher than $8.15 \%$ [6]. After cooling this area remains single-phased. At nitrogen concentration values of $6.1-7.15 \%$, the area of the layer characterized by the presence of the $\varepsilon$ - phase will be free of porosity and also during this phase when slowly cooled, there will occur the separation of the excess $\gamma^{\prime}$ phase. With the increase of the technological maintenance period at the nitriding temperature, the size of the zone $\left(\varepsilon+\gamma^{\prime}\right)$ does not change significantly, being registered only an increase the size of the phase $\varepsilon$ porous area [6]. The increase in the carbon content of the steel determines a significant increase of the $\varepsilon$ phase porous zone.

The diffusion zone (the "internal nitriding" zone) represents the multiple phase area under the $(\varepsilon+\gamma$ ') layer and consists of a solid solution of nitrogen in the base metal, its nitrides and the nitrides of the alloying elements (when they exist). Depending on the affinity for nitrogen of the alloying elements, the diffusion areas are of $1^{\text {st }}$ and $2^{\text {nd }}$ degree [4]; those of $1^{\text {st }}$ degree appear in the case of pure metals and their alloys in which the alloying elements have a lower affinity for nitrogen compared to that of the basic element of the alloy, and on the contrary, those of $2^{\text {nd }}$ degree have a higher affinity compared to it. In the first case, the diffusion area will consist of the solid solution and metal nitrides with the basic role of the alloy, and in the second case they consist of the solid solution, iron nitrides, $\gamma^{\prime}$ and also of nitrides of the alloying elements. $2^{\text {nd }}$ degree diffusion areas appear in iron alloys with $\mathrm{Ti}, \mathrm{Cr}, \mathrm{V}$ alloying elements, nitralloy alloys and in refractory metal alloys. Simultaneously with the increase of the diffusion zone, the coagulation of separate nitrides takes place, a phenomenon which is possible only in the case of the simultaneous diffusion of both nitrogen atoms and those of alloying elements. These atoms have the maximum flux in the area of the metallic layer-matrix interface and consequently the strongest change of the separated nitrides size will be registered at the end of the diffusion area. The consequence of such phenomena / processes is that as the displacement in relation to the metal-average matrix interface, the degree of nitride dispersion decreases. From a thermodynamic point of view, in the case of allied matrices, the formation of nitrides in the diffusion area (internal nitriding area) is also possible due to the participation of the alloying elements carbides. Such a mechanism is triggered in the presence in the metal matrix subjected to nitriding of elements with high affinity for carbon, such as $\mathrm{Ti}$, $\mathrm{Zr}$, Hf, Cr, Mo, etc. For isomorphic crystalline networks the transition of carbides to nitrides becomes possible, and it can be described schematically as follows:

$$
\mathrm{N}+\mathrm{MeC} \rightarrow \mathrm{Me}(\mathrm{CN}) \rightarrow \mathrm{MeN}+\mathrm{C}
$$

The probability of the transition of carbides into different elements nitrides decreases in the following sequence: $\mathrm{Zr} \rightarrow \mathrm{Si} \rightarrow \mathrm{Hf} \rightarrow \mathrm{Ti} \rightarrow \mathrm{V} \rightarrow \mathrm{Nb} \rightarrow \mathrm{Mn} \rightarrow$ $\mathrm{Cr} \rightarrow \mathrm{Fe}$. [1, 4]. According to the information of the specialized literature, the increase of the metallic products exploitation performances can be rendered by a succession of thermochemical processing as titanaliting followed by classical or plasma nitriding $[7,8]$.

\section{Materials and equipment used in research}

The experimental research aimed at highlighting the effects of nitriding subsequent to the titanization of pure technical iron, respectively the alloying steel 34CrAlMo5 (chemical composition within the limits of W1.8507, respectively EN10085). The main aim was to highlight the extent to which titanium and aluminum contained in chemically defined $\mathrm{Ti}-\mathrm{Al}$ compounds in the titanaliting layer influence the kinetics nitrided layer formed.

Samples with dimension 6 X10X20 mm of both materials, after degreasing with isopropyl alcohol, they were titanaliting in a powdery solid medium followed by nitriding in partially dissociated ammonia. To have a reference element, some of the samples were in a simple nitrided variant; In this situation the samples from 34CrAlMo5 steel, prior to nitriding, were improved under the conditions: volumetric martensitic hardening with austenitization at $870{ }^{\circ} \mathrm{C}$ followed by cooling in oil and subsequently returning to $580{ }^{\circ} \mathrm{C}$.

The powdery solid medium used for titanization was composed of: $30 \%$ made of $\left(35 \% \mathrm{TiO}_{2}+25 \% \mathrm{Al}\right.$ $\left.+20 \mathrm{CaF}_{2}+20 \% \mathrm{Mg}\right), 65 \% \mathrm{Al}_{2} \mathrm{O}_{3}$ and $5 \% \mathrm{NH}_{4} \mathrm{Cl}$. Titanaliting was made in refractory steel tin boxes, sealed with clay latches, in a $10 \mathrm{KW}$ electric chamber oven, with dimensions of chamber $300 \mathrm{X} 180 \mathrm{X} 180$ $\mathrm{mm}$, provided with automatic regulation and temperature control system. The processing was performed at $1050{ }^{\circ} \mathrm{C}, 2$ hours of temperature maintenance, followed by slow cooling with the oven off. Nitriding was carried out in a vertical electric oven with the dimensions of the retort of $\Phi 190 \times 600$ $\mathrm{mm}$, of $8 \mathrm{KW}$ installed power, provided with automatic system of regulation and temperature control. The temperature was varied in the range of 540-620 ${ }^{\circ} \mathrm{C}$, below and above the eutectoid transformation temperature in the Fe-N system, and the degree of dissociation of ammonia (measured by 
titration) in the range of $40-70 \%$, a range in which according to experimental findings the amount of adsorbed nitrogen decreases drastically [3].

The results obtained experimentally for both materials were investigated by optical metallography, using a Neophot 32 microscope equipped with Qimaging 01-MP5.0-RTC-CLR -10 color RTV 10 BIT camera connected to a software Struers SCENTIS V 5.6, electronic microscopy, using an FEI F50 Inspect SEM microscope, equipped with EDAX APEX $2 \mathrm{i}$ energy dispersion X-ray spectrometer with Apollo X SDD detector and X-ray diffraction using Rigaku Smart Lab $X$ Ray Diffractometer. Note: In order to perform the metallographic investigations-phase composition, dimensions of the structural components, the samples were prepared metallographically and attacked with the nital reagent $3 \%$.

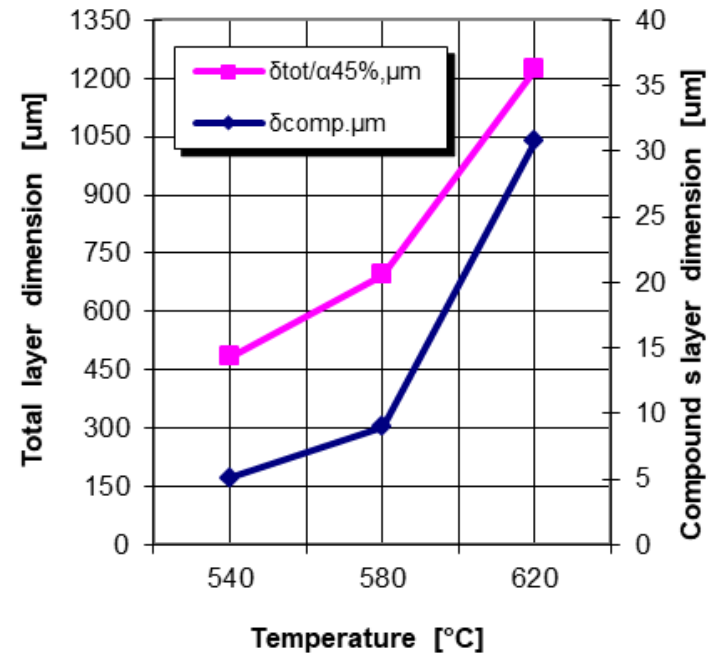

\section{Results of experimental research. Interpretations}

The change of the nitriding medium activity by increasing the degree of ammonia dissociation has immediate repercussions on the kinetics of the layers growth, an aspect which can be observed both in the case of non-alloy matrices (Fig. 1-Fe-ARMCO), and in the case of alloy matrices (image 3-34CrAlMo5). Experimental research has shown that an increase in the degree of ammonia dissociation from $45 \%$ to $70 \%$ affects both the total size of the layer and the area of compounds. The explanation of this phenomenon is based on the behavior of ammonia during heating [11, 13], namely the ionic mechanism of adsorption [12].

\section{Fig. 1. Kinetics growth of different components of nitride layer in technical pure iron depending by} nitriding temperature and the degree of ammonia dissociation (tment-ct $=4$ hours)

Basically, with the increase of the ammonia dissociation degree there decreases the availability of ammonia molecules capable of ionizing by forming $\mathrm{NH}^{3-}$ anionic complexes, which by subsequent decomposition in adsorbed state to ensure the enrichment of the surface layers with nitrogen. The effects of changing the activity of the atmosphere as a result of increasing the degree of ammonia dissociation are highlighted by optical metallography images (Fig. 2) and are amplified by increasing the alloying degree of the metal matrix.

In the case of $34 \mathrm{CrAlMo5}$ steel $(1.12 \% \mathrm{Cr}$; $0.335 \% \mathrm{Mo} ; 0.92 \% \mathrm{Ti} ; 0.64 \% \mathrm{Mn})$ - (Fig 3, 4) the size of the structural components of the nitrided layer under the same conditions as pure technical iron are much lower, the presence of elements with affinity for nitrogen, capable of forming nitrides in the matrix of these steels obviously reduces the availability of nitrogen to contribute to the increase of the diffusion area and of the area of compounds, being more intense, as the ammonia dissociation degree is higher (beyond the optimal range, 20-45\%).

The metallographic analysis of the nitrided layers obtained on the pure technical iron matrices (Fig. 2) at temperatures below the eutectoid transformation temperature of the $\mathrm{Fe}-\mathrm{N}$ system, and different degrees of dissociation (45\%; 70\%), highlights the theoretically anticipated sequence of phases, $\quad \varepsilon+\gamma^{\prime} \rightarrow \gamma^{\prime} \rightarrow \alpha_{N}+\gamma^{\prime}{ }_{\text {exc }} \rightarrow \alpha, \quad$ with slight differences in the size of the different structural components (Fig. 1-2).

In the case of the 34CrAlMo5 alloy improvement matrix, the phase sequence is the same as in the case of pure iron, but the morphological aspect is different and highlighted by the reaction with metallographic reagent (Image 4); the area of 
compounds appears clearly highlighted, and the diffusion area (internal nitriding) can be differentiated from the draw tempered sorbite mass by the chemical reaction differences (it appears to have a much more intense reaction): excess $\gamma^{\prime}$ phase separations (Fe4N and nitrides of alloying elements $\mathrm{CrN}, \mathrm{Mo} 2 \mathrm{~N}, \mathrm{AlN}$, highlighted by X-ray diffraction) are impossible to detect by optical metallography on the draw tempered sorbite background. Obviously, the size of the nitrided layers structural components obtained in the case of the improved 34CrAlMo5 alloy steel is much smaller compared to those made in the case of the nitrided matrix of the pure technical iron under the same conditions (Fig. 3 compared to Fig. 1), the causes being related the presence of alloying elements with affinity for nitrogen.

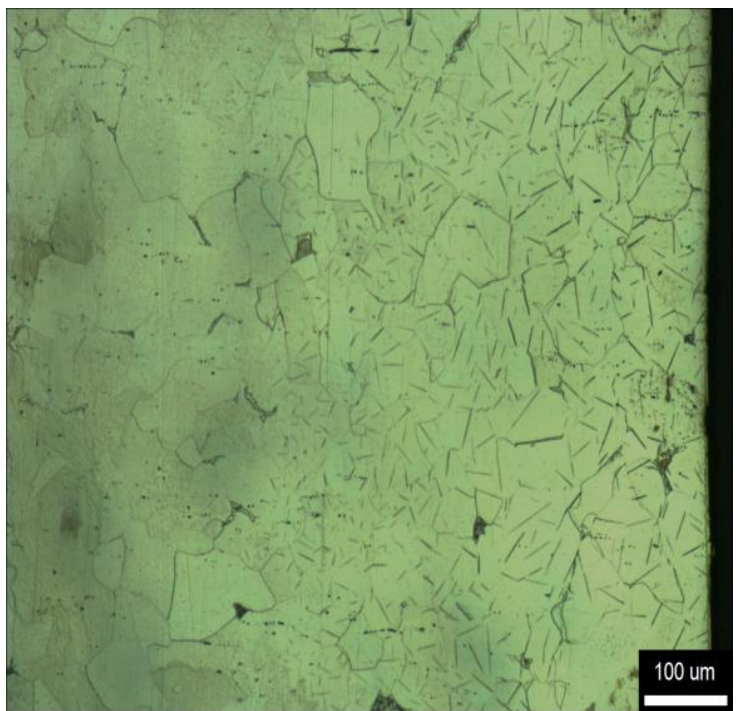

a)

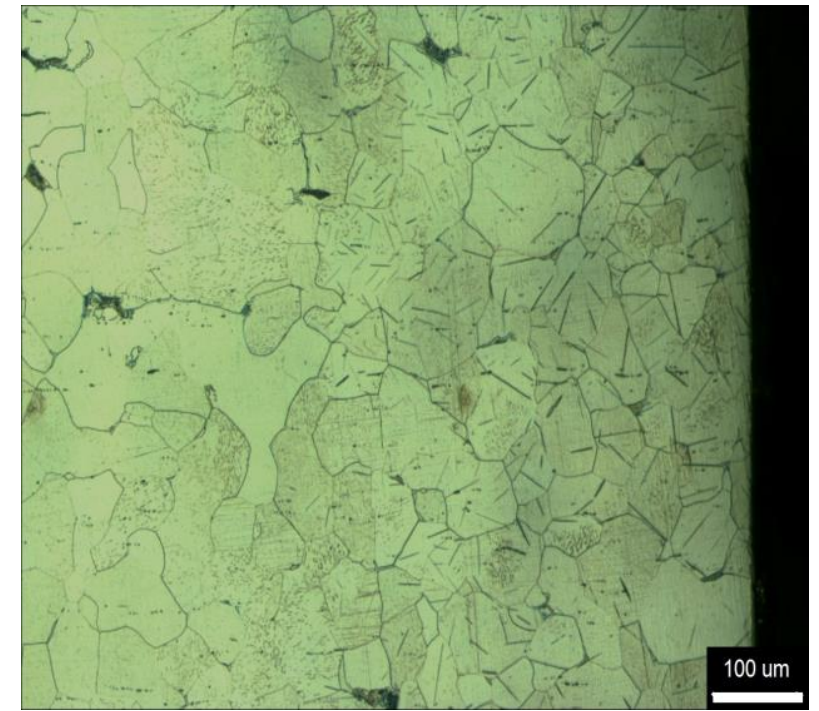

b)

Fig. 2. Structure on the nitriding layer obtained in case of pure technical iron, nitriding in partially dissociation ammonia under conditions: $T=540^{\circ} \mathrm{C} / 4$ ore; $\alpha_{N H 3}=45 \%(a) ; \alpha_{N H 3}=70 \%(b)$.

Attacked reagent: nital $3 \%$
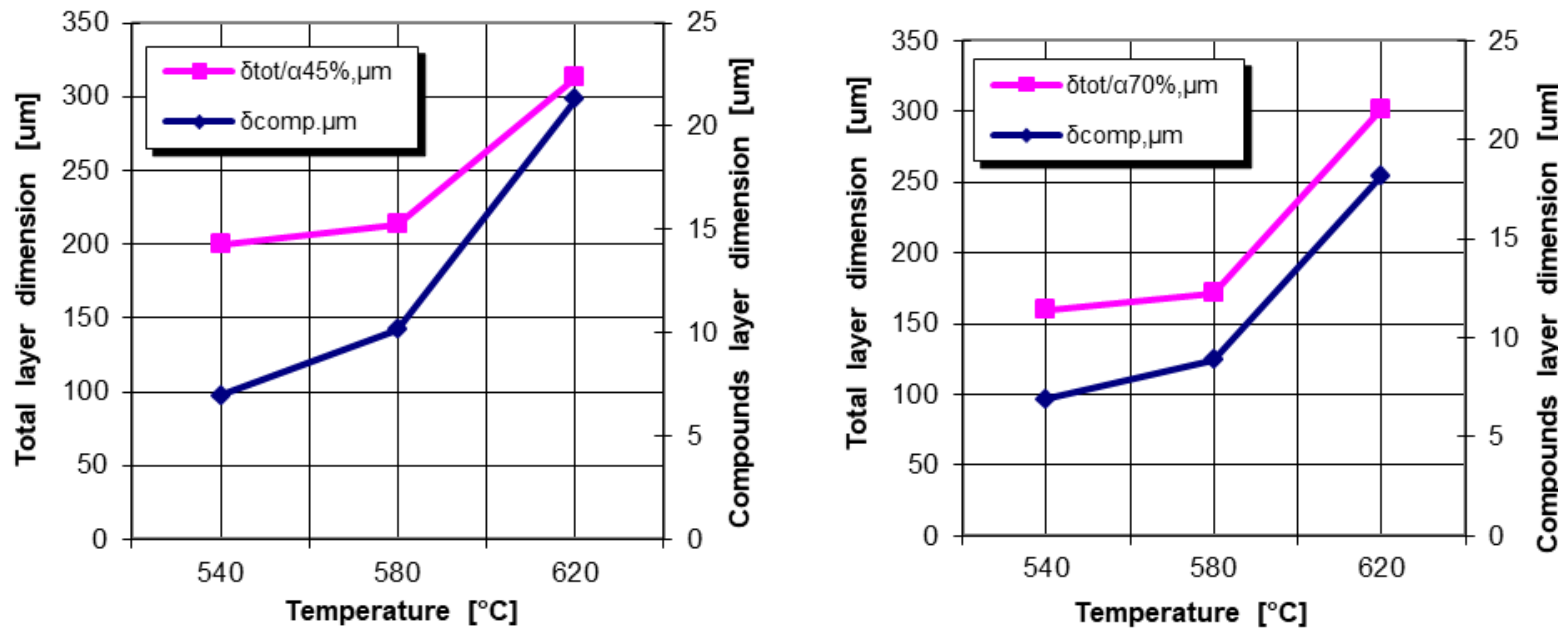

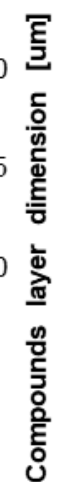

Fig. 3. Kinetics growth of different components of the nitriding layer in the case of 34CrAlMo5 (tment-ct $=4$ hours) 


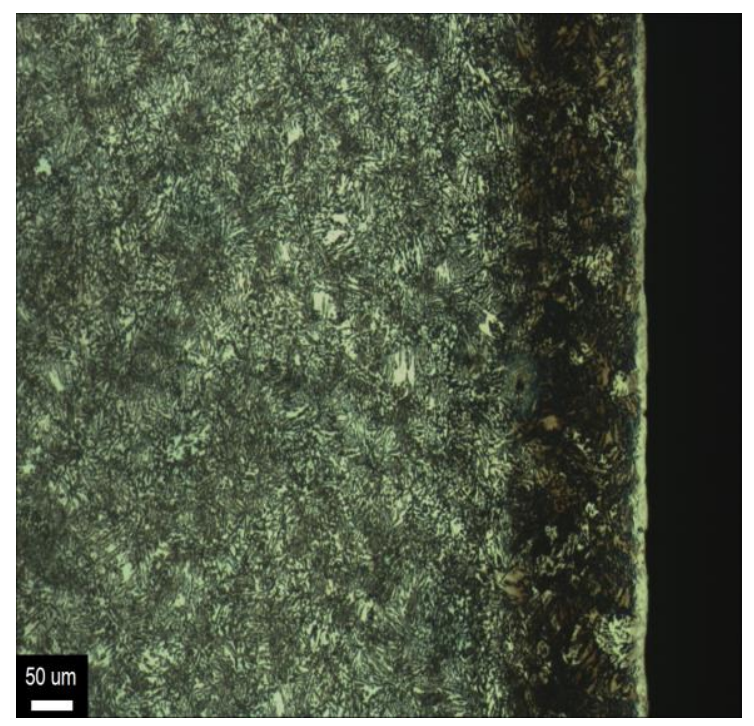

a)

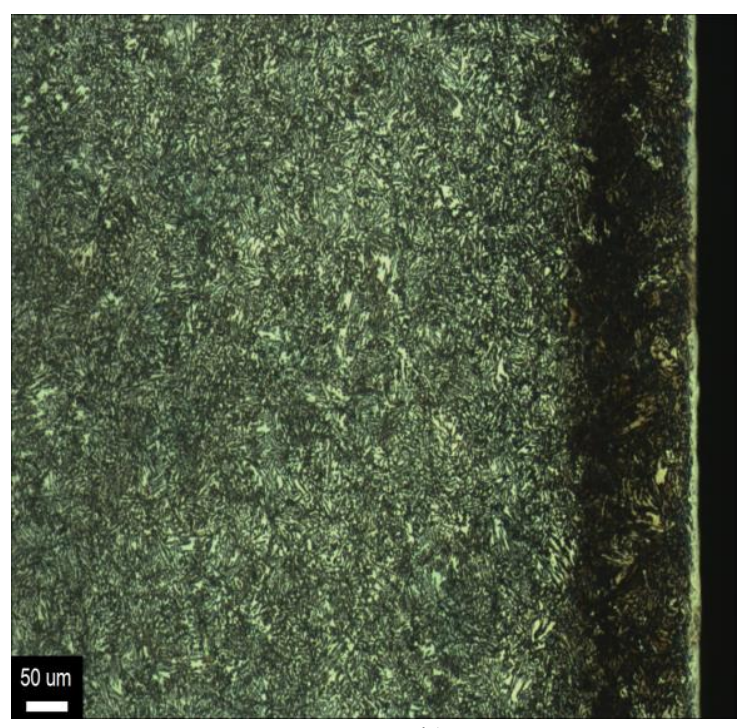

b)

Fig. 4. Structure of nitriding layer obtained in the case of 34CrAlMo5 steel, nitriding in partially dissociated ammonia, under conditions: $T=540^{\circ} \mathrm{C} / 4$ hours; $\alpha_{\mathrm{NH} 3}=45 \%(a) ; \alpha_{\mathrm{NH} 3}=70 \%(b)$. Attacked reagent: nital $3 \%$
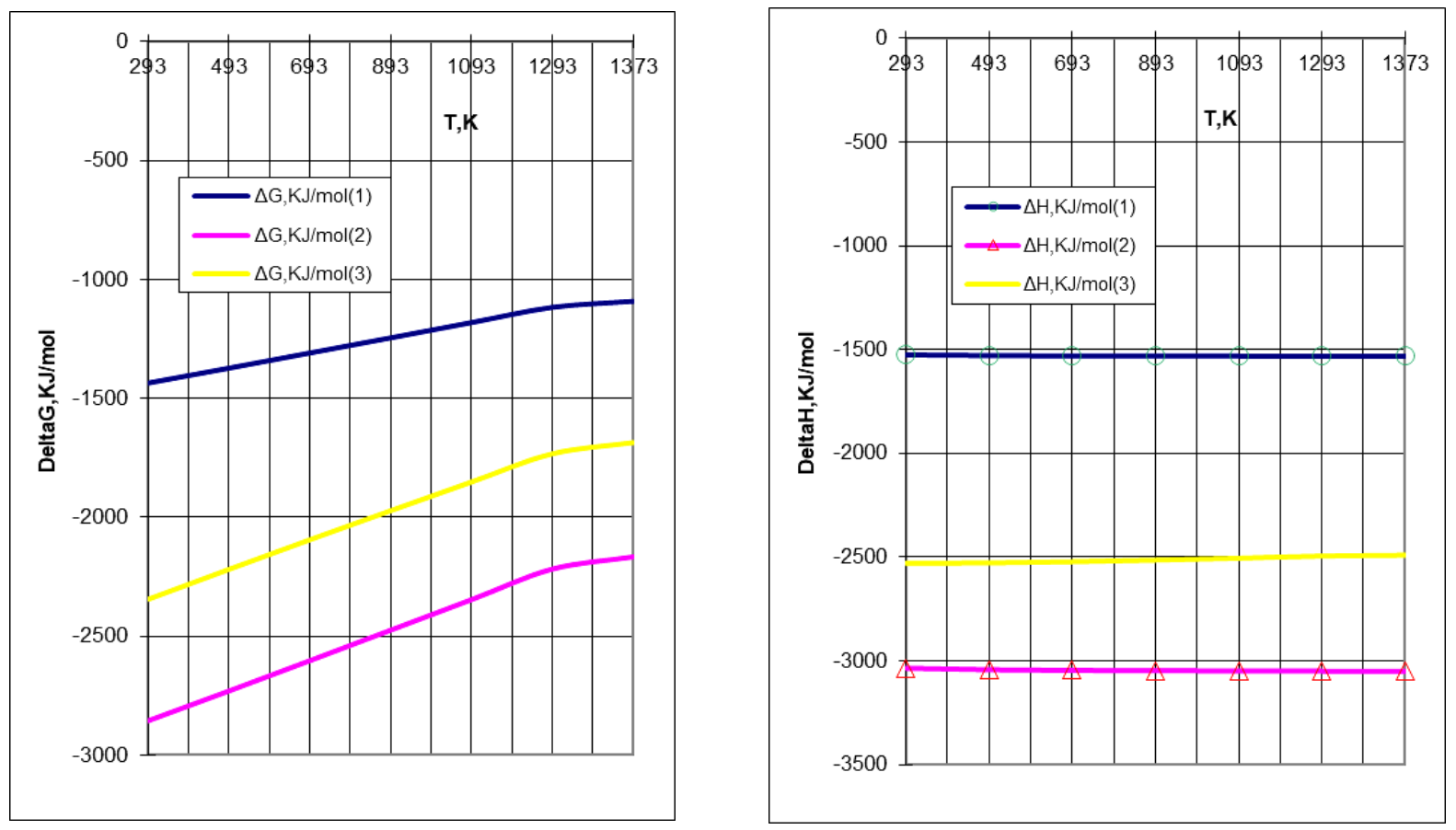

Fig. 5. Temperature variation of the main thermodynamic measurements related to the synthesis reaction of the nitride of the elements initially in the state of chemical compounds defined by Al-Ti Note: Legends notes 1,2,3 correspond to chemical reactions 1-3

In the specialized literature there is information related to the association of chemical processes of titanating and nitriding [7] or nitriding and titanating $[8,9]$, the association of the two manners of thermochemical processing aiming to ensure special performances to the superficial layers of metallic products: microhardness close to $2000 \mu \mathrm{HV}$ or more, special tribological behavior, corrosion resistance in aggressive environments, and others such performances. All these performances seem to be ensured according to the conclusions of various experimental researches by the presence in the superficial layers of the metallic products processed in this way of titanium, aluminum nitrides, or 
complex titanium and aluminum nitrides. Moreover, the nitriding of alloys with high titanium contents, for example of ferritic steels alloyed with titanium, ensures them a substantial increase in the hardness of the surface layers, especially if the $\mathrm{Ti} / \mathrm{C}$ ratio of the steel is within the range 6.4-9.5 [1]. Our own experimental research has led to the conclusion that in the case of a simultaneous surface saturation with titanium and aluminum - titanization of metal matrices - and subsequent nitriding in partially dissociated ammonia, in the surface layers will be found in addition to iron aluminides, $\mathrm{Fe} 3 \mathrm{Al}$, iron nitrides and aluminum, molybdenum, etc. (Fe4N; AlN; TiN, etc.); in the case of matrices alloyed with alloying elements with affinity to nitrogen, after titanating and nitriding, in their layers will be found nitrides. Prior to nitriding titanium aluminides present in the titanium alloyed layer are characterized by high thermal stability, but from the thermodynamic point of view, in the presence of nitrogen the nitride synthesis reactions of the two elements are to be produced (ec. 1-3, Fig. 5), excess nitrogen further participating in the formation and growth of the diffusion area.

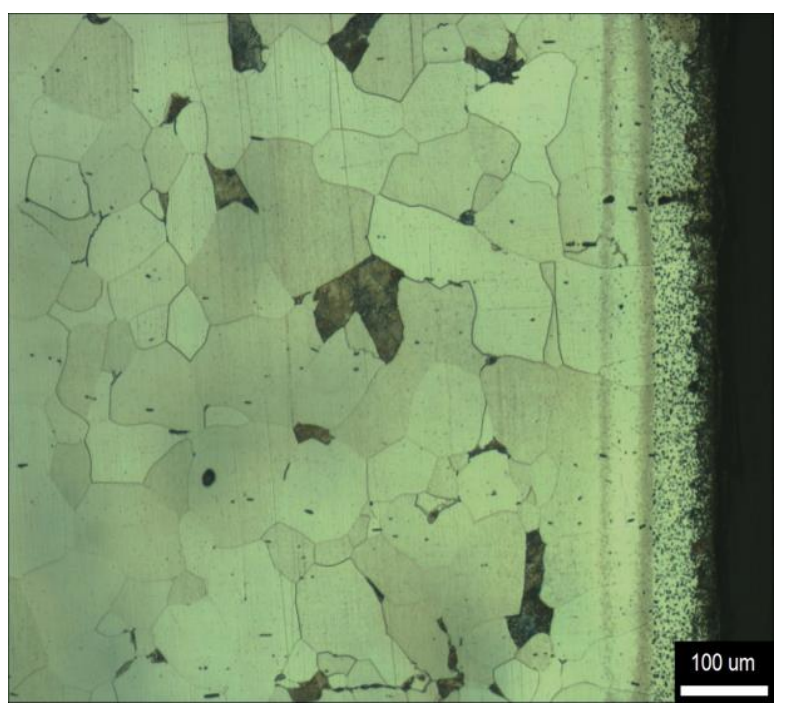

a)

$$
\begin{gathered}
\mathrm{AlTi}+3 \mathrm{~N}(\mathrm{~g})=\mathrm{AlN}+\mathrm{TiN}+\mathrm{N} \downarrow \\
\mathrm{Al}_{3} \mathrm{Ti}+5 \mathrm{~N}(\mathrm{~g})=3 \mathrm{AlN}+\mathrm{TiN}+\mathrm{N} \downarrow \\
2 \mathrm{Fe}_{3} \mathrm{Mo}_{2}+6 \mathrm{~N}(\mathrm{~g})=2 \mathrm{Mo}_{2} \mathrm{~N}+3 \mathrm{Fe}_{2} \mathrm{~N}+\mathrm{N} \downarrow
\end{gathered}
$$

Note: The compound $\mathrm{Fe} 2 \mathrm{Ti}$, which can appear in the titanium alloyed layer, behaves in the presence of nitrogen in the nitriding medium similar to the other compounds (reactions 1-3), the free enthalpy of reactions by which it is converted into iron and titanium nitrides (Fe4N; TiN) being strongly negative in the range of $373 \mathrm{~K}-873 \mathrm{~K}$ and varying in the range $-1822 \mathrm{~J} / \mathrm{mol} \div-1586 \mathrm{~J} / \mathrm{mol}$.

Therefore, the layer of aluminum compounds with titanium (titanium aluminides) formed as a result of the titanaliting process (Fig. 6) is not a barrier for the diffusion of nitrogen, but the reduction of the nitrogen atoms flow as a result of the synthesis reactions of aluminum and titanium nitrides (reactions 1-3 and not only) affects the formation kinetics of both the total layer and the area of compounds (stronger in the case of alloy matrices compared to pure metals).

Fig. 6. Optical microscopy images of Fe-ARMCO(a) and 34CrAlMo5-(b) after titanaliting in solid medium powder at $1050^{\circ} \mathrm{C} / 2$ hours; Attacked reagent: nital 3\%

The titanium containing layers obtained in the case of the two metallic materials, Fe-ARMCO and 34CrAlMo5, have well-defined areas of aluminides; in the case of pure technical iron, the total layer affected by the diffusion of the two elements has sizes of $100 \mu \mathrm{m}$ (Fig. 6a), contains aluminides of iron and titanium (Fe3Al; Fe2Ti; FeTi) and presents porosity in its extremities, phenomenon frequently encountered in titanating solid materials, in contrast to titanized steel 34 CrAlMo5 ( Fig. 6b) for which the area of aluminides of iron and alloying elements, namely their titanium compounds, appears defined by the contrast generated by the reaction with the chemical reagent.

Note: Cooling from $1050{ }^{\circ} \mathrm{C}$ (temperature used for titanating) being done gradually in the oven, with the samples embedded in the powdery solid mixture used as a supplier of active elements, the structure of the 34CrAlMo5 steel matrix will become an annealing structure. 
In order to ensure a level corresponding to the characteristics of the core of this steel, it is necessary to ensure an improvement of these areas before nitriding, in conditions that prevent cracking of the layer during cooling in order to harden the volumetric martensitic. The kinetics of the formation of nitrided layers, after titanating (Fig. 7, 10) is close to the one registered during processing in the absence of titanized layers (Fig. 1, 3), but slightly slower pursuant to the aforementioned reasons. From a morphological point of view, the structure of the layer obtained in the case of pure titanalized and subsequently nitrided technical iron (Fig. 8), is much more suggestive compared to that of the layer in the case of 34CrAlMo5 improvement steel (Fig. 11). The area formed during titanating, namely the diffusion zone (internal nitriding) appear clearly outlined, areas in which iron, titanium and aluminum nitrides were identified by X-ray diffraction, resulting from the interaction of aluminides with nitrogen, and by electron microscopy and quantitative chemical microanalysis (Fig. 13) in the superficial areas of the layer - the areas of compounds - there were identified high concentrations of aluminum $(\sim 6.3 \%$ compared to traces in the initial state) and titanium, namely $(0.74 \%$ compared to traces in the initial state).

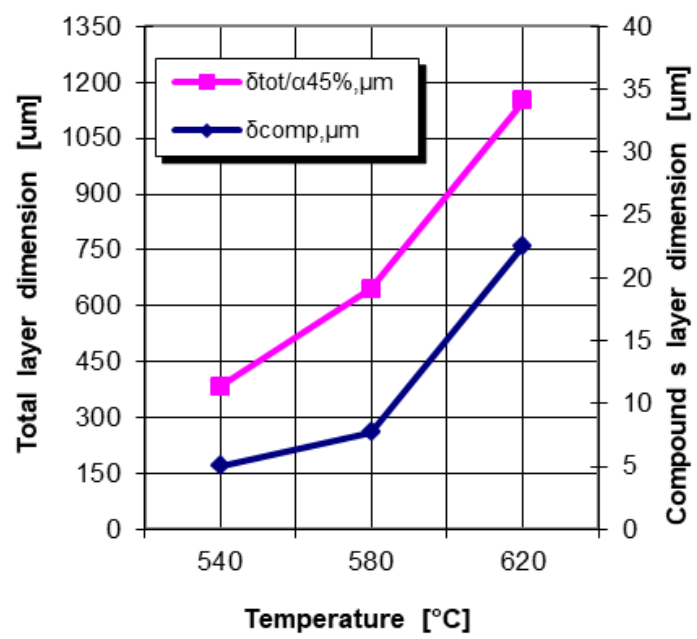

a)

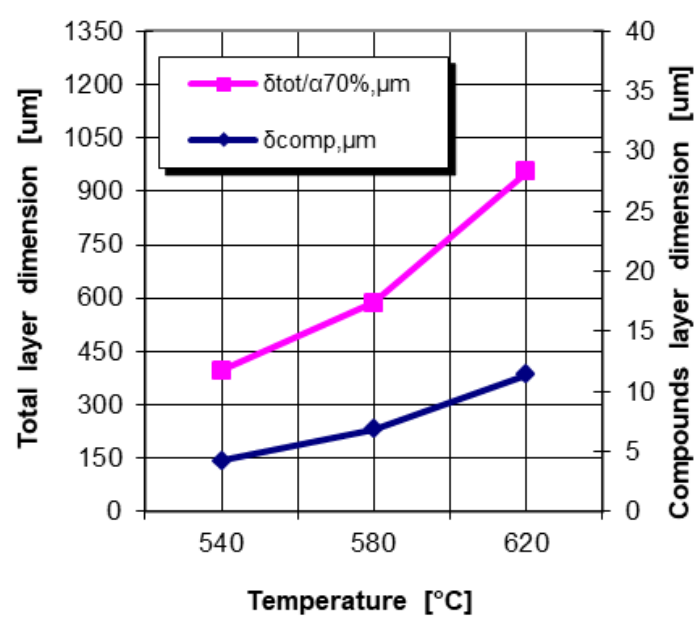

b)

Fig. 7. Kinetics growth of different components on titanaliting layer in solid medium powder (1050 ${ }^{o} \mathrm{C} / 2$ ore $)$ and subsequently nitrided in partially dissociated ammonia $\left(\alpha_{N H 3}=45 \%-\boldsymbol{a} ; \alpha_{N H 3}=70 \%-b\right)$ case of technical pure iron
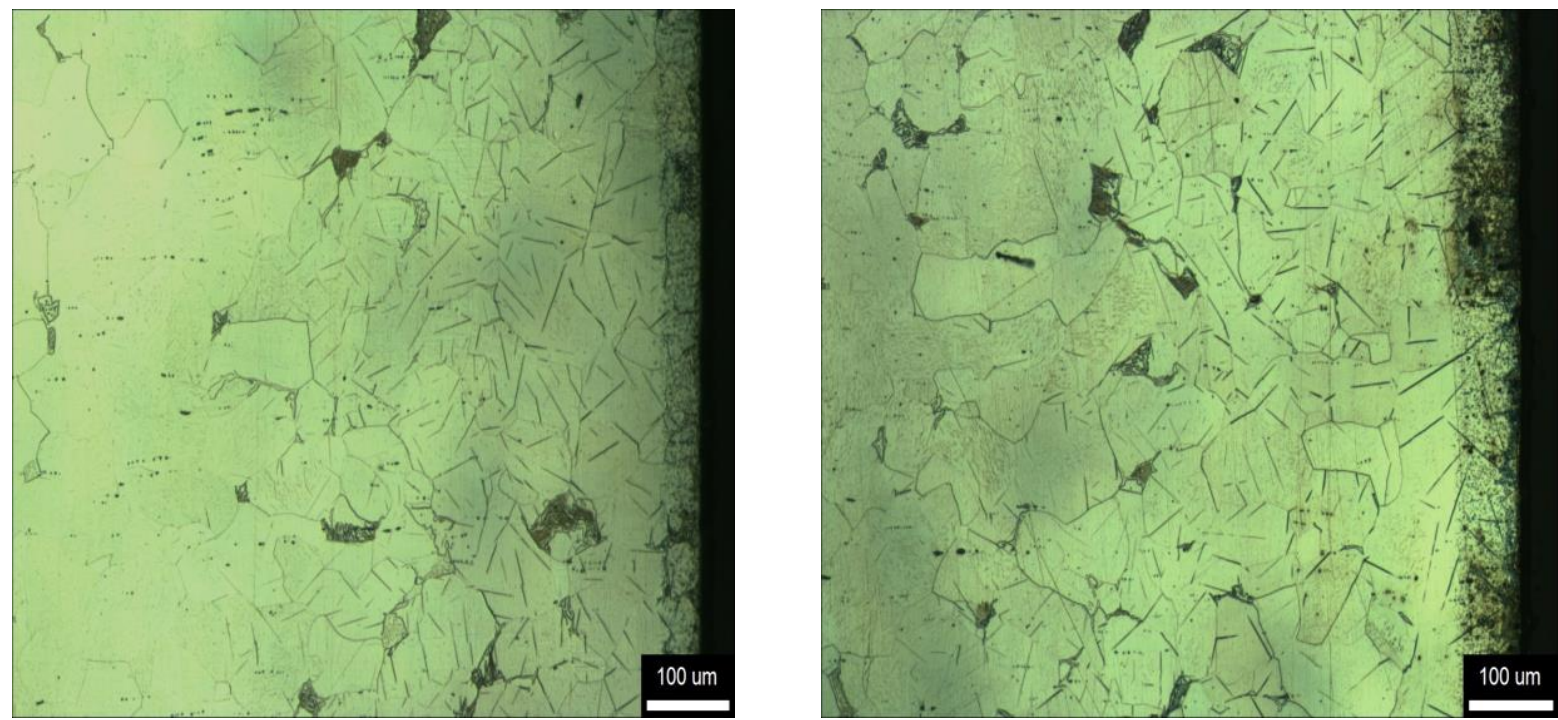

Fig. 8. Optical microscopy of Fe-ARMCO titanaliting in solid medium powder $\left(1050^{\circ} \mathrm{C} / 2\right.$ hours $)$ and subsequently nitriding in partially dissociated ammonia-a) $540{ }^{\circ} \mathrm{C} / \alpha_{\mathrm{NH} 3}=45 \%$;

b) $540{ }^{\circ} \mathrm{C} / \alpha_{\mathrm{NH} 3}=70 \%$; Attacked reagent: nital $3 \%$ 

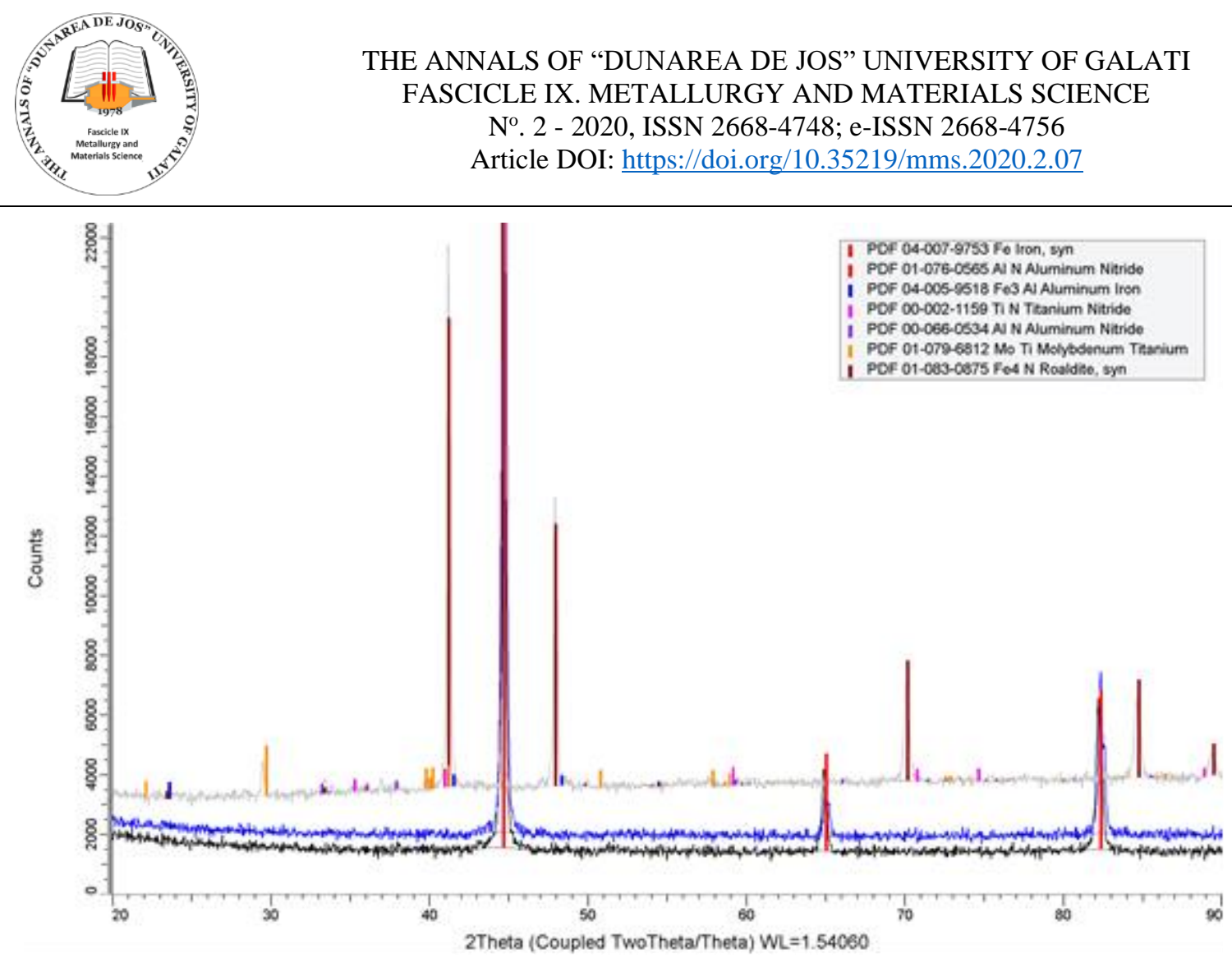

Fig. 9. X-ray diffraction of technical pure iron in solid medium powder $\left(1050^{\circ} \mathrm{C} / 2\right.$ hours $)$ and subsequently nitriding in partially dissociated ammonia $\left(580^{\circ} \mathrm{C} / 4\right.$ hours; $\left.\alpha_{N H 3}=45 \%\right)$ Note: The two basic lines represent the diffraction lines of technical pure iron (reference)

The kinetics of layer formation after titanating and nitriding of the 34CrAlMo5 improvement alloy steel matrix (Fig. 10) is obviously much slower compared to that recorded in the case of pure technical iron (Fig. 7) and slightly slower compared to that recorded for nitriding performed directly to an improved matrix (Fig. 3).

The titanalized and subsequently nitrided layer (Fig. 11), in this case has a morphological aspect close to that following titanating, the differences

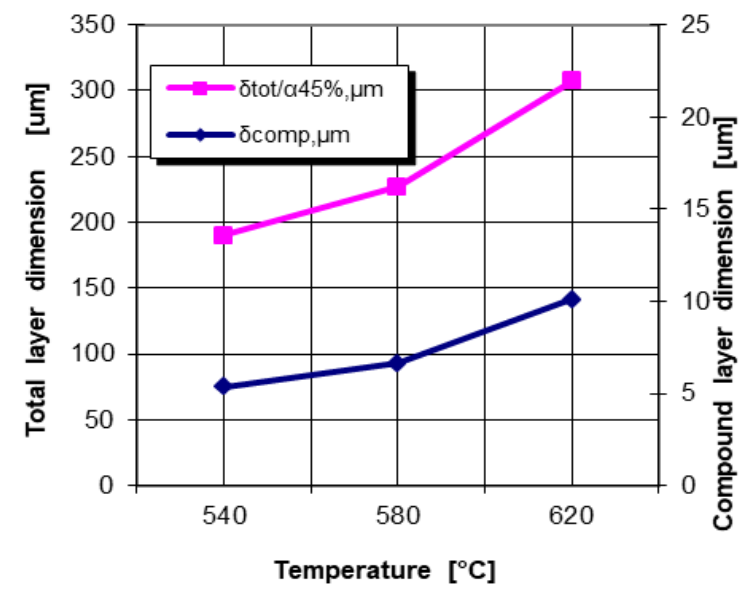

a) being related to the phase composition of the layer: nitrides of aluminum, titanium, iron and molybdenum along with iron aluminide FeAl3 - Fig. 12, compared to the aluminides of iron, titanium, molybdenum or iron titanides of type $\mathrm{Fe} 2 \mathrm{Ti}$, according following titanating. The conversion of these types of compounds after following titanating of 34CrAlMo5 alloy matrix into nitrides during the nitriding process proved to be thermodynamically possible and was confirmed by X-ray diffraction (Fig. 12).

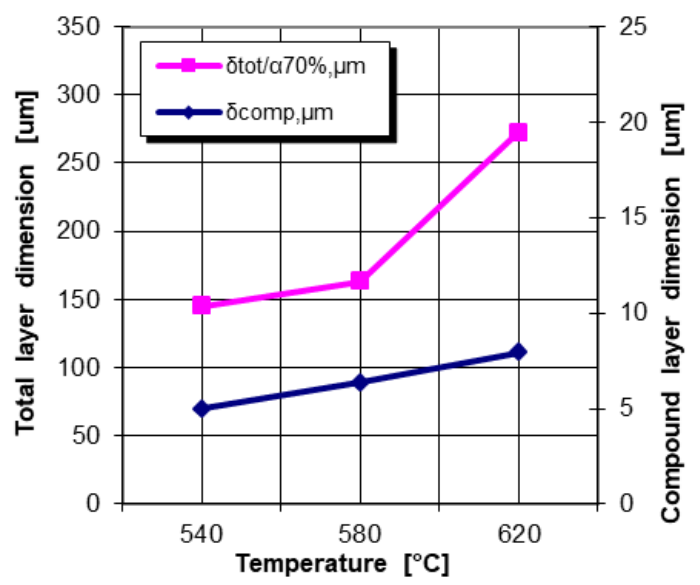

b)

Fig. 10. Kinetics growth components of titanaliting layer in solid medium powder $\left(1050^{\circ} \mathrm{C} / 2\right.$ hours $)$ and subsequently nitriding in partially dissociated ammonia $\left(\alpha_{N H 3}=45 \%\right.$-a; $\left.\alpha_{N H 3}=70 \%-b\right)$ in case of 34 CrAlMo5 steel 


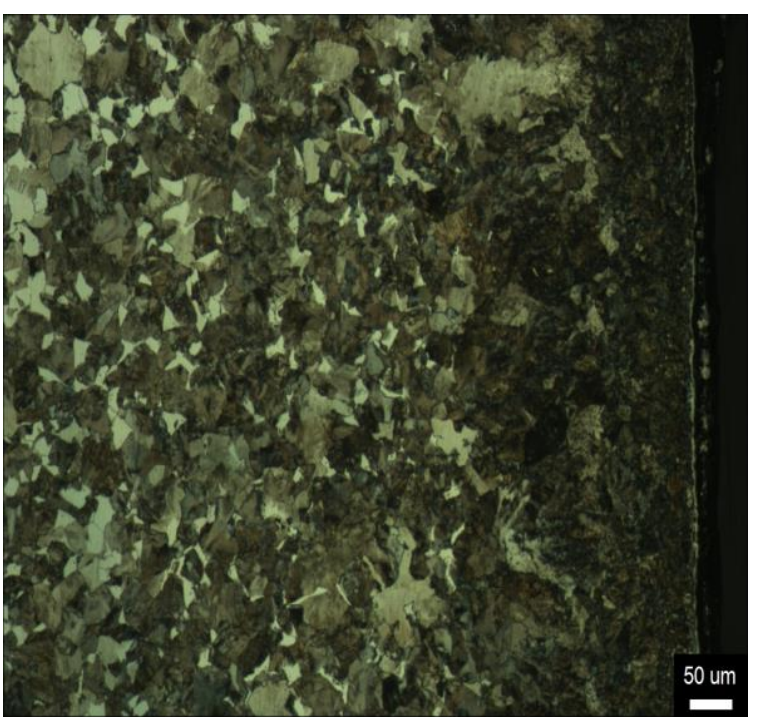

a)

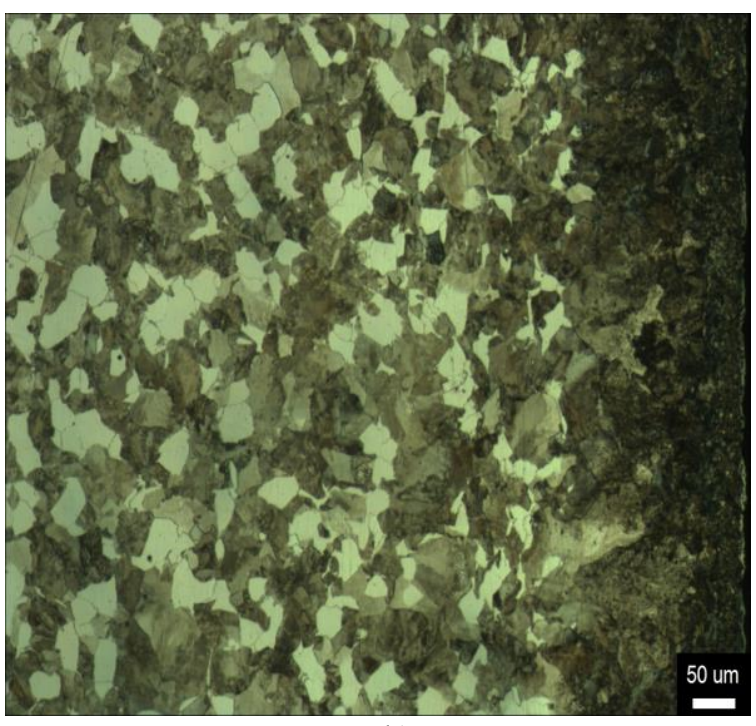

b)

Fig. 11. Optical microscopy of 34CrAlMo5 steel, titanaliting in solid medium powder $\left(1050^{\circ} \mathrm{C} / 2\right.$ hours) and subsequently nitriding in partially dissociated ammonia - a) $540{ }^{\circ} \mathrm{C} / \alpha_{\mathrm{NH} 3}=45 \%$;

b) $540{ }^{\circ} \mathrm{C} / \alpha_{\mathrm{NH} 3}=70 \%$; Attacked reagent: nital $3 \%$

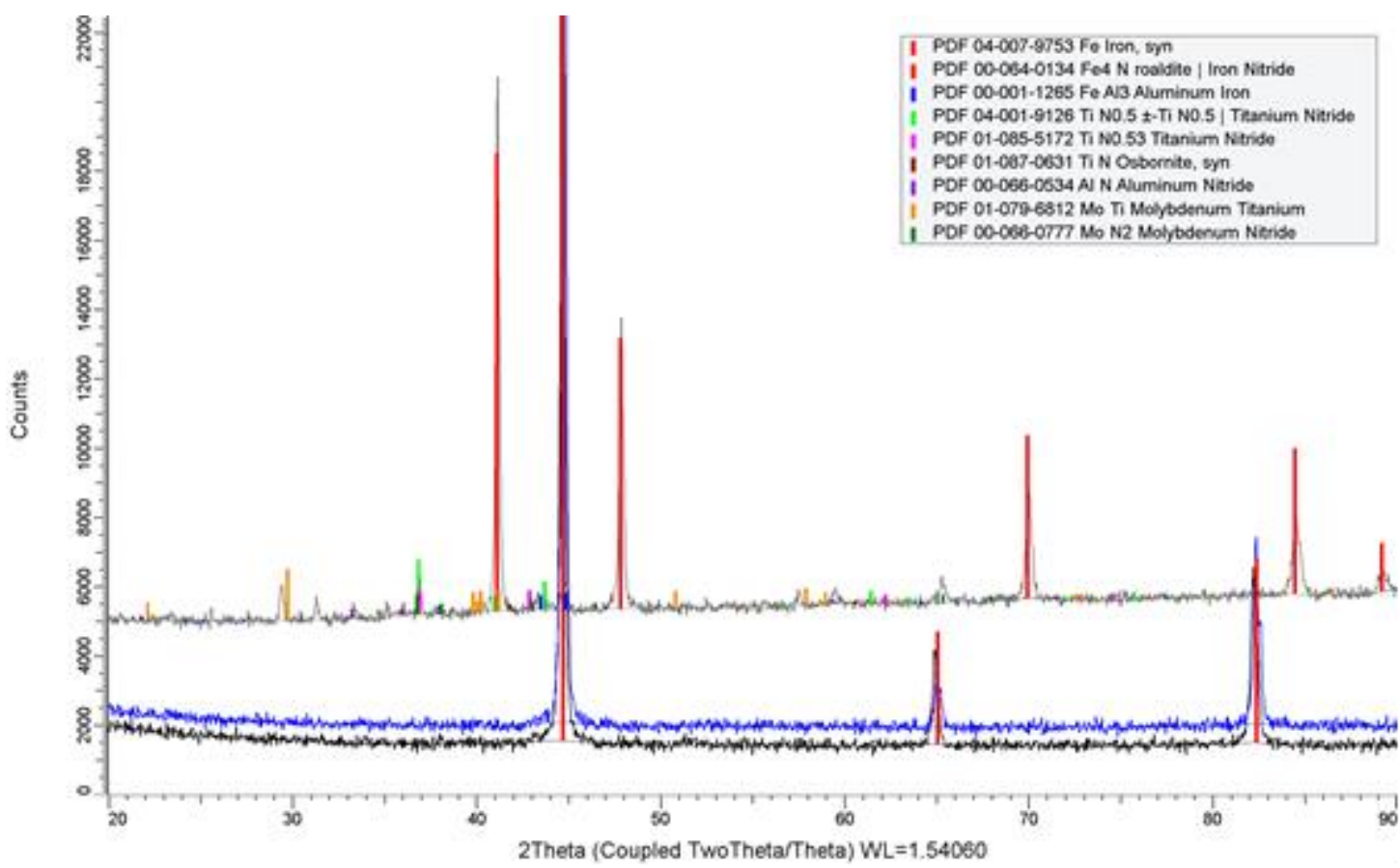

Fig. 12. X-ray diffraction of titanaliting 34CrAlMo5 steel in solid medium powder $\left(1050^{\circ} \mathrm{C} / 2\right.$ hours $)$ and subsequently nitriding in partially dissociated ammonia $\left(580^{\circ} \mathrm{C} / 4\right.$ hours; $\left.\alpha_{N H 3}=45 \%\right)$ Note: The two basic lines represent the diffraction lines of technical pure iron (reference)

Electron microscopy research and quantitative chemical microanalysis (Fig. 1) highlighted the presence of aluminum in high concentrations in the surface areas of the layer ( $15 \%$ compared to $\sim 0.9 \%$ initially) and titanium (0.9\% compared to $0.0005 \%$ in the initial state).
It should be noted that these elements are strictly compiled in the surface areas of the layer - the area of compounds, the variation (decrease) of their concentration on the layer thickness being much faster compared to that recorded in the case of pure technical iron. 
The differences regarding the aspect of the distribution of the two elements in the titanalized and subsequently nitrided layer of the two concerned materials, Fe-ARMCO and 34 CrAlMo5, are dictated by the very different values of the diffusion coefficients related to these elements in an unalloyed matrix, compared to an alloyed matrix.

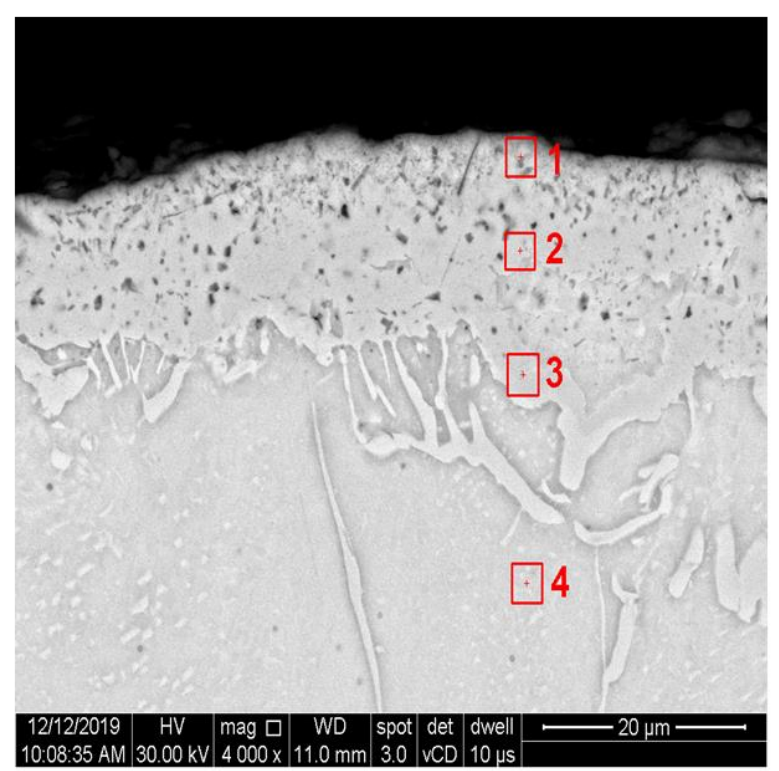

$\mathrm{Al}=6.29 \%(\mathrm{Z} 1) ; 4.69 \%(\mathrm{Z} 2) ; 1.29 \%(\mathrm{Z} 3) \ldots . .0 .0 \%(\mathrm{Z} 4)$ $\mathrm{Ti}=0.74 \%(\mathrm{Z1}) ; 0.75 \%(\mathrm{Z} 2) ; 0.75 \%(\mathrm{Z} 3) \ldots . .0 .0 \%(\mathrm{Z} 4)$

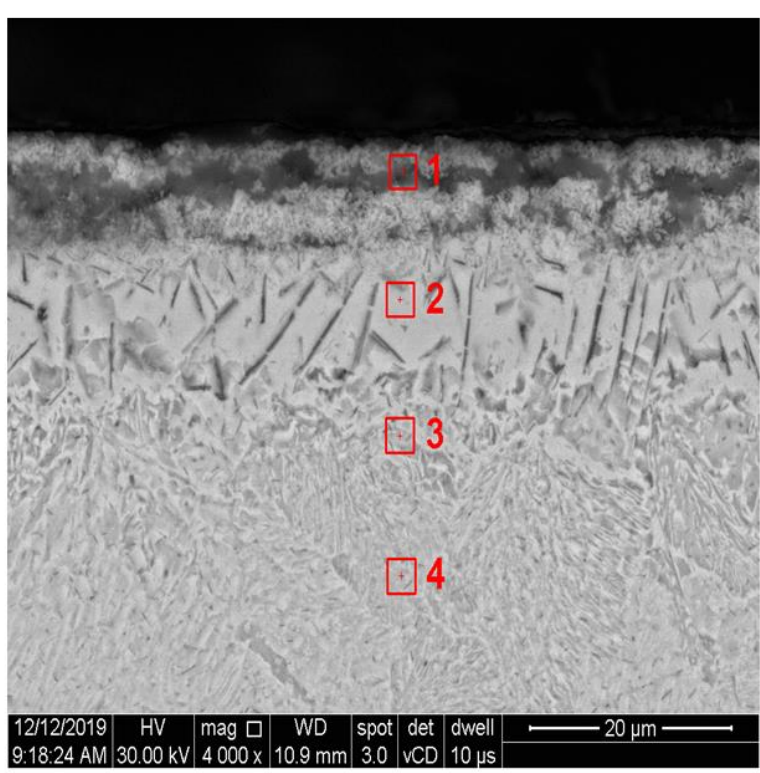

$\mathrm{Al}=15.31 \%(\mathrm{Z1}) ; 2.63 \%(\mathrm{Z} 2) ; 4.15 \%(\mathrm{Z} 3) \ldots 3.12 \%(\mathrm{Z} 4)$
$\mathrm{Ti}=0.90 \%(\mathrm{Z} 1) ; 0.0005 \%(\mathrm{Z} 2) ; 0.0005 \%(\mathrm{Z} 3) .0 .0005 \%(\mathrm{Z} 4)$

Fig. 13. Electron microscopy of technical pure iron and 34CrAlMo5 steel, after titanaliting (1050 ${ }^{\circ} \mathrm{C} / 2$ hours $)$ and nitriding in partially dissociated ammonia $\left(580^{\circ} \mathrm{C} / 4\right.$ hours; $\left.\alpha_{N H 3}=45 \%\right)$, with identification of the chemical composition in different microvolumes on depth layer

The presence of FeAl3 type compounds in the titanalized and subsequently nitrided layer gives it high hardness $\left(\sim 8000 \mathrm{MN} / \mathrm{m}^{2}[14]\right)$, wear resistance, as well as high values for the tensile strength and for compression limit [14]. The tribological characteristics of the titanalized and subsequently nitrided layers obtained on the 34CrAlMo5 matrices are substantially increased by the presence of aluminum, titanium, molybdenum and iron nitrides, as well as by the molybdenum titanide (MoTi).

\section{Conclusions}

Nitriding in a partially dissociated ammonia atmosphere after titanaliting in powder medium is an opportune variant for processing metallic matrices, pure metals or steels, in order to increase the operating performance of the products made from them.

The increase in the level of properties/performances is a direct consequence of the increase in the proportion of hardening phases in the superficial layers of metal products processed in this way, determined by the appearance after titanalitation of chemical compounds Al-Ti,Al-Fe,Fe-
Ti etc. and their subsequent conversion into nitride in the nitriding stage. It is anticipated that tribological characteristics can be substantially increased in this way - hardness, wear resistance, but also corrosion resistance in some situations.

The presence of the titanium layer does not constitute a brake on nitrogen diffusion during nitriding after titanialitation, due to the behavior of the chemically defined compounds formed in the process of alitation in the presence of nitrogen. Thermodynamically it has been demonstrated and experimentally proven that the conversion reactions of these compounds in the presence of nitrogen from the nitride medium, be it titanium aluminids or titaniums of iron, in nitride of these elements, with nitrogen release, are extremely likely. In this way it is also justified the formation of a well-developed diffusion zone, close dimensionally to that obtained by simple nitride, but slightly less dimensional compared to it.

\section{References}

[1]. Lahtin Iu. M., Kogan Ia. D., Azotirovanie stali Moskva, Maşinostroenie, p. 19-44, 1976. 


\section{THE ANNALS OF "DUNAREA DE JOS” UNIVERSITY OF GALATI \\ FASCICLE IX. METALLURGY AND MATERIALS SCIENCE \\ $\mathrm{N}^{\circ} .2$ - 2020, ISSN 2668-4748; e-ISSN 2668-4756 \\ Article DOI: https://doi.org/10.35219/mms.2020.2.07}

[2]. Lahtin Iu. M., Arzamasov B. N., Himico-termiceskaia obrabotka stali Moskva, Metallurghia, p. 141-154, 1985.

[3]. Iurghenson A. A., Azotirovanie v energostroenie Moskva, Maşghiz, 1962.

[4]. Lahtin Iu. M., Kogan Ia. D., Spies H. J., Böhmer S., Teoria $i$ tehnologhia azotirovania, Izd Metallurghia \& Izd VEB Deutscher Verlag für Grundstoffindustrie, p. 144-182, Leipzig 1991.

[5]. J. Zýsk, Gefüge von $\varepsilon$-Schichten carbonitrierter unlergierte Stähle in abhängigkeit von ihrer Kohlenstoffkonzentration, Härterei Technische Mitteilungen, B, p. 319-324, 1976.

[6]. Zâsik Ia., Tatcikovskii Ia., Sulkovskii I., Formirovanie diffuzionnih sloev pri gazovom azotirovanii, Metallovedenie i termiceskaia obrabotka metallov, nr. 6, p. 12-15, 1980.

[7]. Gentao Bu, Yuan Gao, Chenglei Wang, Research on Corrosion Resistance of Titanizing and Nitriding on Carbon Steel in $\mathrm{H}_{2} \mathrm{SO}_{4}$ solution, Materials Science Forum, vol. 704-705, p. 11521160, 2012.

[8]. Ozkan Cegila, Saduman Senb, Formation of Titanium Aluminum Nitride Layers on AISI D2 Steel by Nitro-Titanizing Treatment, $2^{\text {nd }}$ International Advances in Applied Physics and materials Science Congress, p. 109-113, 2012.
[9]. Jiawei Xua, Lingbo Tang, Long Chenb, Study on Microstructure and Mechanical Properties of Nitrided and Titanized Carbon Steel, IOP Conference Series: Materials Science and Engineering, 782, 2020.

[10]. Mittemeijer E. I., Nitriding of binary and ternary iron-based alloys, vol. Thermochemical Surface Engineering of Steels, edited by Mittemeijer E. I. and Somers-Woodhead M. A. J., Publishing in Metals and Surface Engineering, nr. 62, p. 313-354, 2015.

[11]. Florian E., Cojocaru M., Aspecte privind termodinamica şi cinetica disocierii amoniacului in timpul incălzirii la nitrurarea şi carbonitrurarea oțelurilor, Metalurgia, nr. 6, 1978.

[12]. Cojocaru M., Florian E., Cementarea cu azot, rezultat al schimbului de electroni între metal şi ammoniac, Metalurgia, nr. 7 , 1978

[13]. Cojocaru M., Florian E., Comportarea amoniacului in timpul incălzirii, explicate prin mecanismul ionic de adsorbţie, Metalurgia, nr. 9, 1978.

[14]. Mondolfo L. F., Structura I svoistva aliuminievâh splavov, Moskva, Metallurghia, p. 67-73, 1979. 